\title{
Proposta de intervenção psicopedagógica em caso de dislexia a partir das perspectivas do filme "Como Estrelas na Terra"
}

Proposal for psychopedagogical intervention in case of dyslexia from the perspectives of the fillm

"Like Stars on Earth"

Propuesta de intervención psicopedagógica en caso de dislexia desde la perspectiva de la película

"Estrellas en la Tierra"

Recebido: 24/12/2021 | Revisado: 02/01/2022 | Aceito: 10/01/2022| Publicado: 12/01/2022

Vinícius Rodrigues Arruda Pinto

ORCID: https://orcid.org/0000-0001-8935-6377

Instituto Federal de Educação, Ciência e Tecnologia de Minas Gerais, Brasil

E-mail: vinicius.arruda@ufv..br

Jamila Reis Gomes

ORCID: https://orcid.org/0000-0003-4287-2600

Instituto Federal de Educação, Ciência e Tecnologia de Minas Gerais, Brasil E-mail: jamilareisgomes@gmail.com

Felipe Vidigal Sette da Fonseca

ORCID: https://orcid.org/0000-0001-9307-7901

União de Estudos Superiores de Viçosa, Brasil E-mail: fvidigalpsico@ gmail.com.br Marcela de Melo Fernandes

ORCID: https://orcid.org/0000-0002-3324-9414 Instituto Federal de Educação, Ciência e Tecnologia de Minas Gerais, Brasil E-mail: marcela.fernandes@ifmg.edu.br

\section{Resumo}

A Arte terapia é um método que tem como objetivo proporcionar a saúde mental e sua prática incorpora diferentes linguagens artísticas. No presente artigo, objetivou-se fazer um comparativo entre a experiência do protagonista do filme Como Estrelas na Terra, o portador de dislexia Ishaan, e a também portadora de dislexia Clarice, para entender a importância da arteterapia como aliada na intervenção psicoterapêutica. Objetivamos ainda entender como a institucionalização do sistema educacional atual interfere na educação inclusiva, contribuindo para o desenvolvimento de neurose noogênica em estudantes com dislexia. Nesse contexto, o papel que a família enquanto instituição também é preponderante para promover sensibilização e valorização das formas singulares no processo de ensinoaprendizagem de portadores de dislexia. A partir da proposição da Terapia de Intenção Paradoxal associada aos recursos arte terapêuticos propusemos uma intervenção no caso Clarice, tendo a arte como aliada no alvorecer do sentido da vida. A aplicação prática do presente trabalho é potencializar maneiras singulares do processo de livre criação-aprendizagem, sobretudo a partir do desfecho de Ishaan, propiciando mudanças nas esferas afetivas, interpessoais e relacionais de estudantes com dislexia.

Palavras-chave: Dislexia; Arteterapia; Logoterapia; Aprendizagem.

\begin{abstract}
Art therapy is a method that aims to provide mental health and its practice incorporates different artistic languages. In this article, the objective was to compare the experience of the protagonist of the film Like Stars on Earth, the person with dyslexia Ishaan, and the dyslexia patient Clarice, in order to understand the importance of art therapy as an ally in psychotherapeutic intervention. We also aim to understand how the institutionalization of the current educational system interferes with inclusive education, interfering with the development of noogenic neurosis in students with dyslexia. In this context, the role of the family as an institution is also preponderant in promoting awareness and valuing the unique ways in the teaching-learning process of dyslexia patients. From the proposition of Paradoxal Intention Therapy associated with therapeutic art resources, we proposed an intervention in the Clarice case, having art as an ally in the dawn of the meaning of life. We hope that this work can enhance unique ways of the free creationlearning process, especially from Ishaan's outcome, providing changes in the affective, interpersonal and relational spheres of students with dyslexia.
\end{abstract}

Keywords: Dyslexia; Art therapy; Logotherapy; Learning. 


\section{Resumen}

La arteterapia es un método que tiene como objetivo brindar salud mental y su práctica incorpora diferentes lenguajes artísticos. En este artículo, el objetivo fue comparar la experiencia de la protagonista de la película Estrellas en la Tierra, la persona con dislexia Ishaan, y la paciente con dislexia Clarice, para comprender la importancia de la arteterapia como aliado en la intervención psicoterapéutica. También pretendemos comprender cómo la institucionalización del sistema educativo actual interfiere con la educación inclusiva, interfiriendo con el desarrollo de la neurosis noogénica en estudiantes con dislexia. En este contexto, el papel de la familia como institución también es preponderante en la promoción de la conciencia y la valoración de las formas singulares en el proceso de enseñanza-aprendizaje de los pacientes con dislexia. A partir de la propuesta de la Terapia de Intención Paradójica asociada a los recursos del arteterapêutico, planteamos una intervención en el caso Clarice, teniendo al arte como aliado en los albores del sentido de la vida. Esperamos que este trabajo pueda mejorar las formas únicas del proceso libre de creación-aprendizaje, especialmente a partir del resultado de Ishaan, proporcionando cambios en las esferas afectiva, interpersonal y relacional de los estudiantes con dislexia.

Palabras clave: Dislexia; Arteterapia; Logoterapia; Aprendizaje.

\section{Introdução}

O uso de abordagens não farmacológicas, como a arteterapia, está em ascendência, principalmente diante da preocupação de estarmos vivendo em uma sociedade cada vez mais lançada à medicalização como via de acesso rápido contra a dor. A arteterapia é um tratamento psicossocial amplamente aceito, notadamente aplicável em contextos que envolvem a melhoria da atenção, humor, ansiedade e cognição (Lee et. al., 2019; Shella, 2018), principalmente quando existe algum grau de dificuldade associado à aprendizagem (Lee et. al., 2019).

As saídas criativas, como a arte, as práticas corporais (yoga, meditação, dança, entre outras), podem ser usadas como uma forma de terapia, já que elas são representações da expressão de tensões, problemas ou conflitos humanos (Cristina \& Aneta, 2012). A capacidade de projeção está associada ao simbolismo, e a arteterapia permite trazer o inconsciente à superfície para que o indivíduo possa vivenciar a catarse, mitigando as emoções negativas a partir de um novo olhar da dificuldade vivenciada (Freud, 1996). Nesse sentido, um indivíduo portador de dislexia percebe o fim último daquilo que ele experimenta no seu cotidiano, podendo lidar melhor com a sua dificuldade na compreensão de textos, dificuldades na linguagem oral, instabilidade motora e distúrbios de atenção (Elmarakbi, 2017).

No contexto escolar, o uso de arteterapia tem sido uma ferramenta adequada para melhoria do comportamento social de crianças (Schweizer et al., 2020), principalmente porque a arte pode ser vivenciada no contexto de dinâmicas em grupo, que estimulam as crianças a explorarem a infinidade de universos plurais e possíveis de criação; inevitavelmente, a arte gera um ambiente de grupo mais igualitário, pois trabalha o imaginário individual e coletivo (Teoli, 2020).

Os avanços da arteterapia em intervenções clínicas são notórios. Cucca et al. (2021) avaliaram pacientes com sintomas de Parkinson e perceberam que a arteterapia melhora as habilidades visuais-cognitivas gerais e as estratégias de exploração visual, bem como a função motora geral. Já Oh e Chung (2021) perceberam que a arteterapia aliviou o trauma psicológico em uma criança com Doença de $C r o h n^{l}$, permitindo a ela ter mais autonomia para entender melhor a sua doença e a lidar com ela, de modo que a sua adesão ao tratamento foi também significativamente melhorada. Intervenções no âmbito da educação especial e inclusiva são ainda escassas, mas o uso da arteterapia com alunos disléxicos tem sido uma importante ferramenta para melhorar a capacidade de aprendizagem.

A arte e o design ajudam as crianças a lidar e compreender o mundo frequentemente confuso e complexo da dislexia, pois, a resposta aos estímulos sensoriais induz a criatividade e promove a autoexpressão e a autoestima (Elmarakbi, 2017). O mesmo autor afirma que as composições geométricas simplistas de peças de arte interativas melhoram as habilidades de resolução de problemas de crianças disléxicas. Deste modo, disléxicos são capazes de encontrar fluidez ao responder ao seu ambiente, o que lhe permite lidar melhor com os obstáculos contra a dislexia, e consequentemente impactando positivamente em sua saúde mental e bem-estar. 
Por meio da arteterapia, crianças com dislexia também podem compreender como conviver com a dislexia, sobretudo aprendendo a lidar com as experiências emocionais subjacentes. Ao se lançarem na arte, os disléxicos percebem que a criação está além das palavras e dos números, tendo a oportunidade de compensação emocional perante a falta de recursos que eles enfrentavam antes de utilizar a arteterapia como aliada.

Com base nas premissas apresentadas, este estudo foi conduzido como um estudo de caso único (Caso Clarice) para fazer um comparativo entre a experiência do protagonista do filme Como Estrelas na Terra, o portador de dislexia Ishaan, e a também portadora de dislexia Clarice, e assim entender a importância da arteterapia como aliada na intervenção psicoterapêutica. Objetivamos ainda entender como a institucionalização do sistema educacional atual interfere na educação inclusiva, interferindo no desenvolvimento de neurose noogênica em estudantes com dislexia.

Nesse sentido, desenvolvemos as seguintes questões de pesquisa:

1. Como as instituições escola e família moldam o comportamento social dos disléxicos e como contribuem nos casos Ishaan e Clarice?

2. Que tipo de experiências psicológicas relacionadas à existência uma criança com dislexia vivencia?

3. Qual o significado que a arteterapia exerce na autodeterminação e autoeficácia de uma criança com dislexia?

\section{Metodologia}

Este projeto é baseado em duas etapas qualitativas distintas, sendo a primeira uma resenha crítica do filme "Como estrelas na terra", de autoria de Aamir Khan e Amole Gupte, e a segunda composta por uma análise documental de um caso de paciente dislexo que sofreu intervenção da arteterapia. A abordagem adotada para a metodologia será pautada na arteterapia junguiana como auxílio psicopedagógico na manutenção da dislexia dentro dos contextos escolares (Souza, 2010).

A elegibilidade do filme baseou-se na característica central da obra, que apresenta o recorte da vida de um aluno com dislexia, suas dificuldades, seu contexto familiar, e uma exposição crítica dos sistemas educacionais dentro da perspectiva de problemas de aprendizagem (Santos, 2018). O estudo de caso será escolhido como etapa suplementar à etapa 1, considerando um cenário real em que se pauta o efetivo uso da arteterapia como instrumento de intervenção.

Adotaremos uma abordagem qualitativa de triangulação de dados, a partir da análise intercruzada de informações entre as duas etapas, considerando as transcrições literais de entrevistas ocorridas entre paciente e psicólogo, evidências documentais deste caso e transcrições literais de falas do filme, para melhorar a qualidade dos resultados. A evidência documental como artigos, sites e mídias sociais também serão consideradas fontes a serem trianguladas com os resultados das etapas 1 e 2, visando melhorar a precisão dos resultados (Lovell, 2016).

\subsection{Procedimento experimental}

O estudo de caso foi realizado em uma cidade situada no sudeste do estado de Minas Gerais, a partir de análise documental, seguindo recomendações de análise de caso descritivo que, segundo Andrade (2002), preocupa-se em observar os fatos, registrá-los, analisá-los, classificá-los e interpretá-los. As abordagens descritivas têm o objetivo da descrição das características de uma população, fenômeno ou de uma experiência. Para Sá-Silva et. al (2009, p. 5) "a pesquisa documental é um procedimento que se utiliza de métodos e técnicas para a apreensão, compreensão e análise de documentos dos mais variados tipos".

O filme Como Estrelas na Terra, direção de Todd Phillips envolve a arte como o prisma de intervenções psicoeducativas no contexto da dislexia e espelha comportamentos semelhantes aos observados no caso Clarice. O filme conta a história de um menino indiano de oito anos de idade, Ishaan, que sofre de dislexia, sofre deboche de professores e alunos, 
inclusive do pai que demonstra um comportamento rígido e cético frente ao problema de aprendizagem demonstrado pelo filho. Diante de um sofrimento intenso que o garoto passa, inclusive enfrentando a não adaptação ao colégio interno, surge o professor Nikumbh, que olha devagar para a sua situação e dá início a mudanças promissoras na vida de Ishaan, incluindo mudanças expressivas na instituição, que atinge alunos, professores e familiares.

O foco de Nikumbh é suscitar, através de um concurso de arte, expressões artísticas, incluindo pitadas de humor. É por meio do concurso que Ishaan se destaca e uma conscientização coletiva toma conta do espaço. A partir da observação do filme, realizamos um recorte de algumas questões essenciais da experiência de Ishaan com comparando-o ao trabalho desenvolvido na clínica. A partir da análise do filme destacamos algumas unidades conceituais que são fundamentais no manejo com aqueles que sofrem pelas dificuldades de aprendizagem associadas a dislexia. Os tópicos são os seguintes:

i. A dor de Ishaan por não ser compreendido;

ii. A dificuldade de relacionamento com o pai;

iii. Sentimento de fracasso e inutilidade ante a escola;

iv. Dificuldades de dar sentido à sua condição após perceber que não consegue realizar as mesmas atividades que seus colegas;

v. Intolerância da instituição, dos colegas, professoras e do próprio pai;

vi. Desconhecimento de habilidades particulares, autodeterminação e autoeficácia.

O referencial teórico da logoterapia de Viktor Frankl dará subsídios para uma interpretação do filme em torno dos pontos acima citados. Foco específico será dado às unidades retiradas do filme, destacadas em prol de contribuir para a compreensão clínica da experiência de Clarice, que apresenta dificuldades semelhantes no contexto do ensino-aprendizagem. Retroalimentaremos o trabalho com o uso de vinhetas narrativas, ilustrações de falas provenientes do filme e do relato clínico, com o intuito de enriquecer a discussão dos pontos apresentados.

\subsection{História de caso}

Uma entrevista preliminar com a participante e os pais foi realizada pelo psicólogo F.V. S. F. para coletar informações sobre o ambiente e o estado psicológico da participante para o tratamento. O psicólogo compartilhou o documento da entrevista por e-mail, o qual foi reestruturado para descrição do caso:

i. Nome fictício Clarice, uma menina do terceiro ano do ensino fundamental, 8 anos de idade, que mora em uma cidade do sudeste de Minas Gerais com seus pais. A entrevista preliminar revelou que os pais da paciente entraram em contato relatando queixas de baixo rendimento escolar da filha após indicação da escola.

ii. A mãe relatou ter passado mal durante os 9 meses de gestação. Aos 3 meses de gestação, ela discutiu com o tio e achou que tinha perdido o bebê. Episódios de depressão pós-parto também lhe acometeram. O primeiro dia de aula de Clarice foi desesperador para a mãe. Não fez uso de drogas durante a gravidez.

iii. Clarice, identifica bem as letras, mas possui uma leitura silábica, arrastada e com trocas frequentes de letras especificamente o P com o B, e o F com o V.

iv. Os pais também relatam que Clarice, na maioria das vezes, fica desatenta e ansiosa antes e durante a realização de tarefas escolares, principalmente no processo de leitura e escrita. $\mathrm{Na}$ escrita, segundo os pais a paciente possui escrita aglutinada e a ortografia fora dos padrões; palavras como espaguete e elefante são escritas como 'paguete' e 'levante'; segundo a mãe: "chega ser quase impossível ler uma palavra que ela escreve!”. Eles 
também afirmam que Clarice é muito inteligente para tarefas manuais e artísticas, o que vem chamando muito a atenção do casal. Também se destaca por suas boas competências em realização de operações matemáticas, mas, quando é preciso resolver problemas matemáticos, Clarice se perde completamente.

v. Segundo o pai, se a professora fizer uma leitura pausada por Clarice, ela consegue resolver muito bem as questões matemáticas, além de solucionar bem problemas e compreender os textos nas aulas de português. "Parece que ela tem uma boa memória auditiva, mas na hora de ler se perde completamente".

vi. Em relação ao sono, range os dentes, tem dificuldades para dormir e já afirmou não saber porque a noite existe. Em geral, dorme entre 21:00 e 21:30 horas. O horário do despertar costumeiramente ocorre às 9 horas, com muita dificuldade. Nas palavras dos pais: "É muito difícil acordá-la cedo".

vii. Os pais acrescentam: "A escola não sabe como conduzir esse processo com nossa filha, precisamos de um Diagnóstico Psicopedagógico para nos dar um norte no processo de aprendizagem de nossa filha".

\section{Resultados e Discussão}

\subsection{A institucionalização das escolas}

Não é possível falar sobre arteterapia sem investigar o contexto escolar. Não podemos deixar de destacar o movimento danoso da instituição: manter professores e alunas/es/os institucionalizados, seguindo uma direção única em uma estrada sem possibilidade de vias de acesso. Segundo Bleger (1974), a instituição é, muitas vezes, resultado de uma doutrina já estabelecida onde as práticas instituintes acabam sendo instituídas de forma hierarquizada. Uma citação de décadas atrás e, ao mesmo tempo, tão atual.

No topo da hierarquia geralmente estão aqueles que não pisam nos "terreiros da escola", impedindo que a instituição seja um espaço criativo, aberto ao novo, dinâmico e construtivo. Obviamente não podemos generalizar, mas o "saber" costumeiramente está aprisionado nas mãos daqueles que impõem a verdade absoluta na instituição (Sampaio \& Sampaio, 2009). Nesse sentido, os institucionalizados são submetidos a concepções ideológicas que se sobrepõem aos seus pensamentos, vontades ou tentativas. Por isso, não é de se surpreender que nós, enquanto sociedade, estejamos carregados de introjeções que nos levam a reprovar aquilo que aparentemente foge aos padrões. Exemplo mais notório que podemos destacar é a atuação da psiquiatra Nise da Silveira que, ao se deparar com a rigidez da instituição contra as psicoses, deu vida nova aos seus pacientes ao unir a possibilidade deles se encontrarem com seus próprios arquétipos através da arte.

Correlacionando com a atuação do Nise da Silveira o Filme "Como Estrelas na Terra", os colegas de Nikumbh o satirizam, questionando-o sobre a bagunça que os alunos estão fazendo em sua aula, e comparando-a a uma feira livre. Ao que ele responde:

"Eles são crianças, senhor, é natural. Se não expressarem suas emoções numa aula de arte, onde mais expressarão?" (Como Estrelas na Terra, 2017).

Neste trecho vemos como a resistência criada dentro da instituição está arraigada no repertório dos professores que, ao questionar Nikumbh sobre a sua didática, o advertem sobre a disciplina que deve ser respeitada na escola. Quase que de maneira contingente eles dizem, por entre linhas, que: se eu faço arte, logo estou sendo indisciplinado. E se estou sendo indisciplinado, então estou agindo contra a instituição escola. Ou pior, quando Nikumbh compromete-se a dedicar-se a Ishaan, o diretor desta escola parece considerar uma perda de tempo, mesmo sabendo da lei que defende a inclusão de aluno com necessidades especiais em escolas regulares: 
“Então uma escola especial é o seu lugar" (IBIDEM, 2017).

A este respeito, quando os pais de Clarice dizem que "a escola não sabe como conduzir esse processo com nossa filha, precisamos de um Diagnóstico Psicopedagógico para nos dar um norte no processo de aprendizagem de nossa filha", percebemos na fala que eles estão expressando que não recebem o retorno esperado da instituição para fazer o papel dela enquanto tal: se estamos falando de escola, estamos falando de um local que ensina, e que sobretudo, ensina os portadores de transtornos, deficiências, superdotação, dentre outras. Se ela não é capaz de ensinar a todos, de promover o desenvolvimento de todos, algo está errado desde a sua gestão. Baremblitt (1992) ressalta-se que:

As instituições são lógicas, são árvores de composições lógicas que, segundo a forma e o grau de formalização que adotem, podem ser leis, podem ser normas e, quando não estão enunciadas de maneira manifesta, podem ser pautas, regularidades de comportamentos (Baremblitt, 1992, p. 27).

O cerne do problema da institucionalização está no fato de que o portador de dislexia se sente inadequado diante das exigências da escola e dos pais, muitas vezes caindo na "rebeldia" ou na "fantasia" (Sampaio \& Sampaio, 2009), como podemos notar no filme na fala do pai de Ishaan, porque ele foi forçado a adotar esse comportamento como subterfúgio, fugindo da sua realidade, que não lhe oferece recursos para lidar com a impotência da dislexia. A situação chega a ficar caótica, a ponto de Ishaan demonstrar sinais notórios de solidão, beirando à depressão. Clarice já demonstra sinais de baixo rendimento escolar e, assim como Ishaan, não tem tido a instituição como aliada, mas como um potencializador de adoecimento.

Ross (2021), em seu estudo conduzido com jovens disléxicos na Inglaterra percebeu que, mesmo com a Lei de Crianças e Famílias de 2014, e o Código de Prática de Necessidades e Deficiências Educacionais Especiais (SEND) em vigor, institucionalmente esses jovens são influenciados pelas políticas da instituição, bem como pela forma como os adultos, sobretudo professores, exercem domínio sobre eles. As representações sociais de poder entre professor e estudante são entraves à capacidade da pessoa com dislexia de exercer agência em sua própria jornada educacional e fazer contribuições significativas para os processos de tomada de decisão. Em outras palavras, esses jovens são limitados porque dependem do posicionamento dos adultos em relação à dislexia, e têm relativamente poucas oportunidades de fazer mudanças de forma independente ou negociar aspectos de provisão relacionados à sua dislexia.

Segundo S'lungile et al. (2020), grandes restrições impedem a visão educacional que ressoa através da premissa de que "nenhuma criança é deixada para trás"; segundo o seu estudo conduzido no continente Africano, tempo insuficiente para dedicar ao aluno com dislexia, atitudes pouco acolhedoras, falta de apoio e falta de formação de professores para lidar com alunos disléxicos eram os fatores que mais emergiram do contexto escolar. Em países mais desenvolvidos não foram encontrados cenários muito destoantes. Não é surpreendente que no filme Ishaan tenha sido enxergado como apático, um "distraído crônico" ou incapaz, não despertando a atenção de professores e alunos, ironicamente é justamente o aluno com deficiência física que decide se aproximar e oferecer amizade.

Spyropoulou (2020) ressalta que visões polarizadas a favor e contra as escolas tradicionais e especiais têm sido amplamente discutidas por professores, pais e alunos, mas ainda não alcançamos uma opinião unânime sobre se o que está sendo ofertado é mais benéfico para o aluno dislexo do que especial. Em estudos conduzidos na Irlanda e nos Estados Unidos, $\mathrm{o}$ autor ressaltou que existem professores resistentes a acreditar que o aluno com dislexia precisa de uma atenção direcionada para as suas dificuldades enfrentadas, ao passo que existem professores que lutam pelo desenvolvimento profissional para a formação de professores e o desenvolvimento de práticas inclusivas. 


\subsection{O suporte familiar e a sua influência no manejo da dislexia}

Clarice traz um histórico materno que merece atenção: a gravidade conturbada de sua mãe, marcada por atritos e momentos de estresse pós-traumático. Os mecanismos subjacentes aos ocorridos na gestação são difíceis de mensurar em termos de proporção que possam ter afetado a capacidade de Clarice de lidar com situações que fogem ao seu controle, como as decorrentes da dislexia. Contudo, não são desconhecidos os efeitos que um binômio gestação conturbada/acometimento de dislexia pode causar numa criança, se forem levados em consideração as dificuldades provenientes da sua condição, como rendimento e autoeficácia na aprendizagem, e as demandas afetivas que da mãe dependem.

O cerne da análise proposta por Winnicott (2002) é a relação mãe-bebê, que preceitua que, a partir do meio ambiente criado pela mãe, a saúde mental do indivíduo moldado na primeira infância é substancialmente afetada e construída. Essa é a mãe que atende as demandas do bebê e, de maneira simbólica, é o papel que Nikumbh faz através da ausência do pai de Ishaan e que também o psicoterapeuta acaba assumindo em decorrência de mecanismos de transferência que a criança, no caso a Clarice, pode vir a demonstrar na falta de um suporte afetivo (Freud, 1996). Portanto, esse ambiente que Winnicott (2002) trata é aquele que tem influência decisiva no psiquismo precoce, crescimento emocional do bebê. Dessa forma, esse ambiente seria as qualidades da mãe fornecidas como suporte para o desenvolvimento da criança em todas as esferas, mas sobretudo na psicológica.

O cuidado materno, a preocupação materno-primária representa o ambiente materno que cria as necessidades específicas do bebê, onde ele possa evoluir e desenvolver seu processo de crescimento e amadurecimento. A sustentação confiável do ambiente garante que a linha da vida e da sustentação da criança não se rompa. De certa forma, embora Ishaan tenha vivenciado de forma diferente a relação familiar, tendo tido um histórico de um relacionamento conturbado com o pai e não tenha tido histórico de problemas com a mãe, o ambiente familiar acabava sendo muito desfavorável. Nesse sentido, podese considerar que a mãe de Ishaan, sendo muitas vezes passiva diante do comportamento autoritário do marido para com Ishaan, contribuiu para que ele se sentisse impotente dentro da própria casa. Se o ambiente for bom o suficiente, então as tendências hereditárias do bebê podem se beneficiar e alcançar resultados favoráveis. Em contrapartida, um ambiente desfavorável, marcado pela passividade da mãe pode ter prejudicado o senso de proteção da criança (Winnicott, 2002). No caso de Clarice, pode-se levantar ainda a questão de conexão com o self do bebê, que estabelece então a relação com o objeto, por isso a teoria das relações objetais.

De maneira mais prática, Clarice pode apresentar um ego desfortalecido porque desde o ventre existe uma cisão dela com o seu referencial (a mãe), o que pode acarretar falta de segurança, baixa autoestima e sensação de abandono, fraqueza. Segundo Pereira e da Silva (2021), baixa autoeficácia está associada às dificuldades acadêmicas, baixa autoestima e a presença de sintomas ansiosos e depressivos em estudantes com dislexia, sendo necessário o seu fortalecimento para garantir evolução no processo de aprendizagem.

\subsection{Diagnóstico estrutural do caso Clarice: Em busca de sentido}

"O sentido é, pois, uma silhueta que se recorta contra o fundo da realidade" (Frankl, 2016, p. 35)

Clarice e Ishaan, dois portadores de dislexia que, se postos um diante do outro, teriam muito mais a dar que receber. Se tomarmos a metafísica de Aristóteles, lançando mão dos conceitos de ato e potência, conseguiremos perceber que os seus múltiplos "modos de ser", paradoxais à realidade unívoca e determinada a que foram submetidos por sua condição dislexia. Em potência, Clarice certamente possui habilidades próprias que podem ser colocadas em ato, mas, por estar imersa em um cenário de sentido puramente horizontal (sucesso/fracasso) (Frankl, 2016), sua capacidade de encontrar os valores que lhe conferem as possibilidades de sentido mais elevadas (dimensão vertical) está prejudicada. Por exemplo, fora reportado que 
Clarice possui habilidades artísticas, mas ela não entende como colocar o seu potencial em ato. Em se tratando do diagnóstico estrutural de Clarice e Ishaan, não se pode pensar em trabalhar terapeuticamente a evolução perante a dislexia sem mencionar o princípio da Teoria das Quatro Causas de Aristóteles (Aristóteles, 2012).

Imaginemos o ambiente escolar, em que as crianças precisam de cadeiras para se sentar. A cadeira foi feita de madeira (causa material) e adquiriu uma forma (causa formal), mas alguém precisou fazer a cadeira (causa eficiente) para que as crianças pudessem se sentar (causa final). Para além do ato, qual a finalidade das suas ações? Será que Clarice e Ishaan compreendem as causas em seu entorno quando o ambiente escolar e o ambiente familiar lhe oferecem apenas a perspectiva do sucesso ou fracasso? Quer dizer, se alguém lê de forma que não demonstra problema de encadeamento de letras e palavras, não há troca de letras ou números, não demonstra problemas fonológicos e não se mostra com problemas de rendimento escolar, esse aluno é o sucesso ao passo que aquele que não anda no mesmo ritmo é o fracassado? Que perspectiva é essa de ser humano que a sociedade tem criado para além das escolas? É notório que é esse o ambiente institucionalizado a que Ishaan e Clarice se inserem, experimentando, portanto, a ausência de sentido, marcado pelo fato de que, se não correspondem ao que se espera de um aluno considerado "normal", eles são estigmatizados de maneira pejorativa como burro, apático, distraído crônico. Soma-se a isso a exposição de erros em sala de aula e repressão, como no caso de Ishaan que era severamente mortificado e insultado por seu pai. O resultado disso é que essas crianças experimentam um vazio existencial, denominado neurose noogênica.

Como a visão é puramente horizontal, se eles não correspondem àquilo que o ambiente os exige, eles se sentem sem valor, vazios, sem perspectiva de sentido. Segundo Frankl (2016), o problema da sociedade moderna está em se concentrar na dimensão horizontal Homo Sapiens, que deseja ser bem-sucedido, mas desconsidera a dimensão perpendicular a esta, que é a Homo Patiens, onde, mesmo diante de um sofrimento inevitável, é possível avançar no seu pleno sentido de vida.

Na Figura 1 podemos observar as dimensões supracitadas, considerando o modelo de existência e sentido da vida de Frankl (2016). Observe que "Sucesso" foi utilizado de forma figurada para simbolizar ter ou não dislexia, isto é, quem tem dislexia é estigmatizado como aquele que fracassou. Contudo, para fins de discussão, fracasso será considerado sofrimento inevitável, correspondente ao fato de que Ishaan e Clarice não podem evitar a realidade que os cerca. Portanto, na intervenção terapêutica a proposição será conduzi-los ao enfrentamento da realidade, lançando mão dos instrumentos que podem ajudar a lidar melhor com a condição da dislexia. Abaixo a figura 1, mostra um esquema adaptado do modelo de existência e sentido da vida segundo Frankl (2016). 
Figura 1. Proposição de intervenção terapêutica a partir do diagnóstico estrutural de neurose noogênica (vácuo existencial).

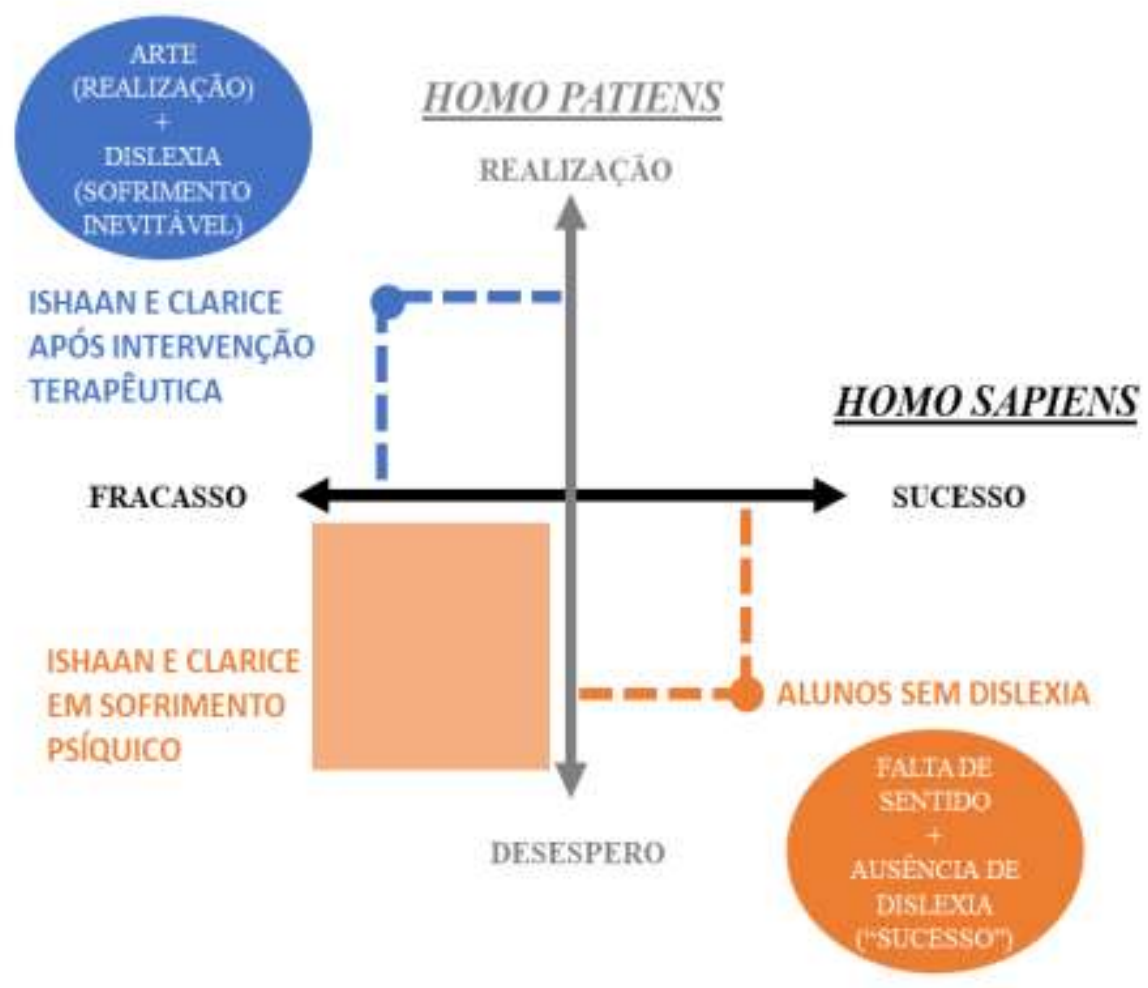

Fonte: Esquema adaptado do modelo de existência e sentido da vida segundo Frankl (2016).

A partir do exposto na Figura 1, existe um contraste representado pela possibilidade de encontrar realização na dor, como também desespero no "sucesso". Por exemplo, um aluno sem dislexia que é extremamente cobrado por seus pais a obter padrões de nota máxima pode experimentar falta de sentido, justamente por não saber a finalidade última de se estudar. Da mesma forma, ainda que Ishaan tenha experimentado o fracasso no seu transtorno, Nikumbh abriu o leque de possibilidades de realização dentro da sua condição inevitável de sofrimento (representado aqui pelo desafio em lidar com a dislexia). De maneira análoga à Clarice, a proposta seria 9eva-la a se conhecer, descobrindo as suas potencialidades que podem ser colocadas em ato, para que ela veja que a sua vida não está determinada pela dislexia. Por exemplo, ao ser matriculada em um curso de educação artística, Clarice poderá desenvolver sua habilidade inata, percebendo as finalidades últimas do seu trabalho, que poderiam ser perceber a sua individualidade, única e irrepetível, a até mesmo poder servir a partir de sua habilidade (por exemplo, vendendo seus quadros para ajudar instituições de caridade).

"A cada passo encontramos homens que, de modo exemplar, conseguiram superar as restrições e limitações iniciais, postas à liberdade pelo fator biológico, isto é, as dificuldades que, a princípio, se opunham ao desenvolvimento do seu espírito. Assim, a sua forma de vida definitiva faz lembrar uma realização artística ou desportiva: uma realização artística, na medida em que a rebelde matéria biológica se foi deixando modelar [...] Contudo, fazer cada qual o melhor $<<$ que puder $>>$, fazer em cada caso o máximo possível, significa: ter em conta, ao ajuizar duma realização, a sua relatividade; apreciá-la em relação ao seu <<start $>>$, em relação à situação concreta, com todas as suas dificuldades, isto é, os impedimentos externos ou inibições internas". (Frankl, 2019; p. 169). 


\subsection{O método da intenção paradoxal aliado à arteterapia como intervenção}

A técnica logoterapêutica de intenção paradoxal visa mobilizar a capacidade de auto distanciar-se do contexto fonte de neurose psicógena (Frankl, 2019). Considerando que Clarice apresenta problemas de rendimento e se "perde completamente" na resolução de problemas matemáticos, podemos afirmar que existe uma dificuldade iminente de lidar com a realidade da dislexia. Segundo os padrões de reação patógenos segundo Frankl (2019), podemos considerar que Clarice experimenta a neurose de angústia pelo temor de errar novamente palavras, cálculos e demais atividades associadas à dislexia toda vez que se vê em uma situação semelhante à que já experimentou. Esse temor de reaparecimento dos erros é acompanhando de ansiedade antecipatória que traz consigo excitação diante de um problema matemático difícil de resolver, por exemplo. Além disso, pode-se considerar que Clarice apresenta estados de neurose compulsiva, já que, pressionada em realizar uma atividade, ideias do tipo: "você vai errar de novo" ou "você não vai conseguir" são comuns de acontecer em alunos que não progridem no domínio da dislexia. Ao mesmo tempo que ela tenta fugir da situação excitatória (neurose de angústia), ela também enfrenta ideias compulsivas (neurose compulsiva).

A partir do exposto, a técnica de intenção paradoxal seria útil na aprendizagem, à medida que se proponha a levar Clarice ao embate com aquilo que é fonte de medo, ansiedade e temor, sobretudo decorrentes de situações em que a dislexia é colocada à prova (Wong, 2002). Todo o entendimento de conquistas de habilidades que poderá ser trabalhado com auxílio da arteterapia facilita, para além do desenvolvimento da inteligência, a segurança egoica de Clarice frente à dislexia. Há que se considerar que uma equipe multiprofissional, como a intervenção de um psiquiatra e nutricionista, é importante para que se possa entender toda a dinâmica psicofísica vivenciada por Clarice. Por exemplo, não adianta aplicar uma técnica psicoterapêutica se existe um desbalanço no nível hormonal de cortisol, que interfere na qualidade do sono.

Dentro da proposição do plano de tratamento, é estabelecido que a consciência fonológica permanece sendo um dos métodos de intervenção mais comuns e eficazes no manejo da dislexia, trabalhando a melhoria de aspectos cognitivos, como memória verbal de curto prazo, fluência verbal fonológica e desempenho de leitura de palavras (Layes et al., 2020; Vender \& Melloni, 2021). Nessa direção, a ludoterapia e musicoterapia também se configuram aliadas à consciência fonológica, já que, a exemplo do que acontece com Clarice, a ludoterapia tem sido demonstrada uma importante ferramenta no aumento da autoestima e melhoria do desempenho acadêmico de disléxicos no que se refere à resolução de problemas de matemática $\mathrm{e}$ leitura (Abbaslo, 2020), enquanto a musicoterapia, segundo Insuasti Salvador (2021), por meio do ritmo permite fortalecer a distinção e a prosódia das palavras, permitindo assim melhorar ou eliminar suas fraquezas a cada fonema que tem um problema, desta forma é possível desenvolver o ouvido e uma boa articulação da linguagem verbal pelos estímulos musicais recebidos pelo cérebro.

Uma das intervenções deste estudo é utilizar a arte como estratégia de ação no caso terapêutico supracitado, já que o filme "Como Estrelas na Terra" buscou esmiuçar a riqueza da arte para debater sobre questões importantes acerca da aprendizagem. São muitas técnicas à disposição da arteterapia, portanto, considerando que Clarice demanda questões como trabalho da criatividade, autoexpressão, sentido de vida e existência, as técnicas mencionadas no Quadro 1 são aquelas que podem envolver um trabalho da expressão corporal e aprimoramento de habilidades que ela já possui com pintura, considerando também a importância para que Clarice desenvolva a capacidade de identificar seus arquétipos pessoais em consonância com o desenvolvimento da sua capacidade de aprender a simbolizar experiências negativas e positivas no manejo da dislexia.

Para investimento no processo de individuação em busca do self, são apresentadas no Quadro 1 técnicas em Arteterapia propostas por Philippini (2020). Considerando que a arte de criar, de pensar em perspectiva, dimensão, construção e modelagem são pressupostos para que Clarice consiga conectar-se com o seu próprio self, o terapeuta poderá levá-la ao aprendizado da simbólica, em que ela consiga simbolizar a experiência e identificar os arquétipos que possui para que alcance 
o domínio de suas habilidades e desenvolva autoeficácia. Nesse sentido também podemos considerar que a construção de narrativas, de poemas e o investimento na pintura em tela poderão ser utilizados como suporte para que Clarice alcance a melhoria da sua autoimagem, autoestima, sentindo-se capaz para explorar os seus próprios recursos pessoais (Da Silva, 2020), que porventura possam ter sido afetados desde o ventre materno.

Para acompanhar o ritmo do paciente adolescente que, muitas vezes, já está imerso no meio tecnológico digital, o terapeuta pode lançar mão de arteterapia voltada para tecnologia digital. Por exemplo, tendo por base o estudo de Nabhan e Kamel (2021), utilizando o aplicativo WhatsApp para aliar arteterapia e disgrafia, propusemos o uso de algum tipo desta ferramenta no setting terapêutico para facilitar a autoexpressão de Clarice com a dislexia, restaurar sua autoconfiança e aprimorar suas habilidades a um nível proporcional à sua aptidão para a manutenção do seu bem-estar psicológico. Desse modo, a exemplo de Ishaan, espera-se que a paciente possa encontrar os recursos para aprender sobre si mesma e transformar a sua própria vida em obra de arte (Dos Reis, 2014).

Quadro 1. Proposição de plano de tratamento com arteterapia como manejo da dislexia.

\begin{tabular}{|c|c|c|c|}
\hline Intervenção terapêutica & Foco & Finalidade & Diagnóstico estrutural \\
\hline Psiquiatra/Nutricionista & $\begin{array}{l}\text { Níveis de vitamina } \mathrm{D}, \\
\mathrm{B} 12 \text {, magnésio, cortisol e } \\
\text { melatonina }\end{array}$ & $\begin{array}{l}\text { Melhorar a resposta ao estresse, } \\
\text { qualidade do sono, ansiedade e } \\
\text { manutenção do ciclo circadiano }\end{array}$ & $\begin{array}{l}\text {-Sono excessivo } \\
\text {-Baixo rendimento escolar } \\
\text {-Estresse e ansiedade antecipatória }\end{array}$ \\
\hline $\begin{array}{l}\text { Terapia de Intenção } \\
\text { Paradoxal }\end{array}$ & $\begin{array}{l}\text { Medo e temor de realizar } \\
\text { atividades educativas }\end{array}$ & Fortalecimento egóico & $\begin{array}{l}\text {-Neurose de angústia e neurose } \\
\text { compulsiva } \\
\text {-Déficits no domínio cognitivo }\end{array}$ \\
\hline Consciência fonológica & $\begin{array}{l}\text { Estrutura silábica das } \\
\text { palavras, identificação e } \\
\text { comparação de sílabas, } \\
\text { recombinação fonológica }\end{array}$ & $\begin{array}{l}\text { Reeducação da leitura e da escrita, } \\
\text { sobretudo na diferenciação das letras dos } \\
\text { binômios 'f-v' e 'p-b', melhoria de } \\
\text { escrita aglutinada e caligrafia }\end{array}$ & -Déficits no domínio cognitivo \\
\hline Ludoterapia & $\begin{array}{l}\text { Dimensão física } \\
\text { psíquica, e } \\
\text { psicomotora }\end{array}$ & $\begin{array}{l}\text { Expressão corporal, desenvolvimento de } \\
\text { capacidade resolutiva, humor }\end{array}$ & $\begin{array}{l}\text {-Déficits no domínio sensório- } \\
\text { motor }\end{array}$ \\
\hline Musicoterapia & $\begin{array}{l}\text { Dimensão afetiva e } \\
\text { psicomotora }\end{array}$ & $\begin{array}{l}\text { Desenvolver capacidade de raciocínio, } \\
\text { criatividade, habilidade motora e } \\
\text { estimulação auditiva }\end{array}$ & $\begin{array}{l}\text {-Déficits no domínio cognitivo } \\
\text {-Déficits no domínio sensório- } \\
\text { motor }\end{array}$ \\
\hline $\begin{array}{l}\text { Artesanato em madeira, } \\
\text { sucata, tecido, arame, } \\
\text { argila e barro - técnica de } \\
\text { construção e modelagem }\end{array}$ & $\begin{array}{l}\text { Dimensão física e } \\
\text { psíquica, cognitiva, afetiva } \\
\text { e psicomotora }\end{array}$ & $\begin{array}{l}\text { Criatividade e promove a autoexpressão e } \\
\text { a autoestima. }\end{array}$ & $\begin{array}{l}\text {-Déficits no domínio cognitivo } \\
\text { (incluindo problemas com a } \\
\text { matemática) } \\
\text {-Déficits no domínio sensório- } \\
\text { motor }\end{array}$ \\
\hline $\begin{array}{l}\text { Construção de poemas e } \\
\text { narrativas }\end{array}$ & $\begin{array}{l}\text { Dimensão bio, psíquica e } \\
\text { espiritual }\end{array}$ & $\begin{array}{l}\text { Criatividade, promover dinâmica da } \\
\text { existência e sentido da vida }\end{array}$ & -Neurose noogênica \\
\hline Pintura em tela e cerâmica & $\begin{array}{l}\text { Dimensão bio, psíquica e } \\
\text { espiritual }\end{array}$ & $\begin{array}{l}\text { Criatividade, promover dinâmica da } \\
\text { existência e sentido da vida }\end{array}$ & -Neurose noogênica \\
\hline $\begin{array}{l}\text { Assistir ao filme Como } \\
\text { Estrelas na Terra }\end{array}$ & $\begin{array}{l}\text { Dimensão psicossocial e } \\
\text { afetiva }\end{array}$ & $\begin{array}{l}\text { Levá-la ao exercício consciente de si } \\
\text { mesma, desenvolver autoexpressão e a } \\
\text { autoestima. Melhoria de sua atitude } \\
\text { dentro do meio social. Estimular } \\
\text { habilidades e virtudes pessoais. }\end{array}$ & $\begin{array}{l}\text {-Dificuldades de relacionar-se na } \\
\text { escola e no ambiente familiar } \\
\text {-Problemas relativos a autoimagem }\end{array}$ \\
\hline $\begin{array}{l}\text { Arte terapia com recurso } \\
\text { de tecnologia digital }\end{array}$ & Dimensões afetivas & $\begin{array}{l}\text { Explorar o inconsciente e questões no } \\
\text { domínio familiar }\end{array}$ & $\begin{array}{l}\text {-Aspectos consequentes de uma } \\
\text { gravidez conturbada e depressão } \\
\text { pós-parto }\end{array}$ \\
\hline
\end{tabular}

Fonte: Abbaslo (2020), Insuasti Salvador (2021), Frankl (2016), Layes et al. (2020), Vender \& Melloni (2021), Philippini (2020). 
A partir do exposto no Quadro 1 a partir das dimensões que emergiram dos estudos dos autores supracitados, podemos considerar que a arte terapia permeia os aspectos biológico, psicológico e espiritual, considerando que existe uma escolha consciente por parte em confrontar com a sua realidade, sabendo das ações que são possíveis de serem implementadas a favor da sua autonomia na lida com a dislexia. Desta maneira, pode-se esperar que a dimensão do Homo Patiens seja estimulada a partir da intervenção conjunta com a Terapia de Intenção Paradoxal. Deste modo, assim como Ishaan, Clarice entenderá que se pode encontrar realização em meio ao fracasso. Vale lembrar que fracasso foi tratado de forma simbólica como a dificuldade em lidar com uma dificuldade de aprendizagem, não significando, no entanto, que a dislexia seja sinônimo de fracasso. Pelo contrário, é parte que concerne subjetividade à individualidade do indivíduo que demanda educação especial e inclusiva.

Segundo Urrutigaray (apud Bordin, 2014, p.3), pensar a arte como campo fértil na condução de novas perspectivas,

[...] o fazer arte implica diretamente nestas mudanças, transformações, pois, estimulam as ordenações de ideias surgidas pela elaboração mental, aquele que tem acesso à arte ou ao fazer artístico, está tendo oportunidade de desenvolver e configurar habilidades, as quais são por sua vez, reveladoras da estrutura cognitiva de quem as realiza, reflete a maneira pessoal de cada um relacionar-se, de ver o mundo e a maneira como está ele.

Desse modo, pode-se esperar que a arte contribuirá na dinâmica de evocação do sentido da vida, não somente em casos de dislexia, mas para aqueles que portam transtornos e dificuldades de aprendizagem. A arte é recurso valioso na busca consciente do indivíduo para a mudança e o ímpeto à autodeterminação e autoeficácia se torna mais facilitado.

\section{Conclusão}

Este artigo apresentou questões teorias e aplicações relativas à arteterapia. Com o estudo de caso de uma paciente com dislexia, combinado com a crítica do filme "Como estrelas na terra", de autoria de Aamir Khan e Amole Gupte, tivemos a intenção de demonstrar as potencialidades dos recursos artísticos como auxiliares no processo educacional.

Dessa forma, considerando o exposto, no contexto educacional, acreditamos que devem ser feitas adaptações necessárias para que docentes vejam caminhos possíveis através da arteterapia como auxiliar em estratégias de acessibilidade, desenvolvimento, autoconhecimento por meio de atividades artísticas, tais como: pintura, colagem, dobraduras, entre outros, as quais promoverão o desenvolvimento de aprendizagem de estudantes.

É urgente criar perspectivas de uma educação inclusiva, que fortaleça a formação profissional e humana, se adaptando às necessidades apresentadas. Além disso, que a educação seja capaz de promover transformação da realidade. Nesse sentido, a arteterapia torna-se uma ferramenta no autoconhecimento.

A utilização da arteterapia no contexto educacional tem condições de promover um leque de possibilidades, pois as atividades artísticas desenvolvem mudanças internas à medida em que desenvolvem habilidades e que por sua vez, deslocam o lugar de um modelo único de aprendizagem.

\section{Referências}

Abbaslo, F. (2020). The Effect of Play Therapy Based on Cognitive-behavioral Approach on Academic Achievement and Self-esteem of Students with Special Learning Disabilities. Pajouhan Scientific Journal, 18(4), 1-8.

Andrade, M. M. D. (2008). Como preparar trabalhos para curso de pós-graduação: noções práticas. In Como preparar trabalhos para curso de pós-graduação: nocões práticas (pp. 150-150).

Aristóteles. (2012). Metafisica. Tradução do português, textos adicionais e notas de Edson BINI. Edipro.

Baremblitt, G. (1992). Compêndio de análise institucional. Rosa dos Tempos.

Bleger, J. P. (1974). ey-Psicologia Institucional-Editorial Pai dos. 
Bordin, V., Schran, L. D. S., \& Dias, T. A. (2014). Arteterapia em Saúde Mental. $6^{\circ}$ Seminário Nacional Estado e Politicas Sociais e $2^{\circ}$ Seminário de Direitos Humanos.

BVS (Biblioteca Virtual de Saúde). (2021). <https://bvsms.saude.gov.br/doenca-de-crohn/>

Cristina, C., \& Aneta, F. (2012). How can we improve the existing assessments used in art therapy. A meta-analysis on art therapy assessments. Procedia Social and Behavioral Sciences, 33, 358-362.

Como Estrelas Na Terra. Direção: Todd Phillips. Produção de Village Roadshow Pictures. Estados Unidos: Warner Bros, 2019. 1 DVD.

Cucca, A., Di Rocco, A., Acosta, I., Beheshti, M., Berberian, M., Bertisch, H. C., \& Ghilardi, M. F. (2021). Art therapy for Parkinson's disease. Parkinsonism \& Related Disorders, 84, 148-154.

Da Silva, C. A. M. (2020). A contribuição da arteterapia para a deficiência física. Gestão \& Educação, 2(1), 29-35.

Dos Reis, A. C. (2014). Arteterapia: a arte como instrumento no trabalho do Psicólogo. Psicologia: Ciência e Profissão, 34(1), 142-157.

Elmarakbi, N. (2017). Art Therapy for Dyslexic Children: Art Therapy. $1^{\mathrm{a}}$ ed. CreateSpace Independent Publishing Platform.

Frankl, V. E. (2016). Sede de sentido. (5a ed.), Quadrante.

Frankl, V. E. (2019). Psicoterapia e sentido da vida. (7a ed.), Quadrante.

Freud, S. (1996). A dinâmica da transferência (1912). Edição Standard Brasileira das Obras Completas, 12, 131-43.

Insuasti Salvador, P. L. (2021). Musicoterapia versus terapias convencionales en el tratamiento de la dislexia fonológica (Doctoral dissertation, Quito: Universidad Hemisferios 2021).

Gil, A. C. (2008). Pesquisa social. Atlas.

Layes, S., Lalonde, R., \& Rebai, M. (2021). Reading-related abilities underlying phonological awareness: A cross-sectional study in children with and without dyslexia. Logopedics Phoniatrics Vocology, 46(3), 110-117.

Lee, R., Wong, J., Lit Shoon, W., Gandhi, M., Lei, F., E. H., K., Kua, E. H., Rawtaer, I., \& Mahendran, R. (2019). Art therapy for the prevention of cognitive decline. The Arts in Psychotherapy, 64, 20-25.

Lovell, J. L. (2016). How parents process child health and nutrition information: a grounded theory model. Appetite, 97, $138-145$.

Molaei, F. (2021). Investigating the dyslexia of primary school students and presenting educational strategies by combined method. Journal of Educational Studies, $18,59-68$.

Nabhan, R., \& Kamel, N. (2021). Technologically Enhanced Art Therapy: Introducing a New Synergistic Model to Enhance Morphological Awareness in Students with Dysgraphia. LingLit Journal Scientific Journal for Linguistics and Literature, 2(1), 1-8.

Oh, H. R., \& Chung, Y. J. (2021). A single case study of art therapy in a child with Crohn's disease. The Arts in Psychotherapy, 72, 101751.

Pereira, M. D., \& da Silva, J. P. (2021). Fatores associados à autoeficácia, ansiedade e depressão em estudantes disléxicos: revisão integrativa da literatura. Revista Thêma et Scientia, 11(2), 59-78.

Philippini, A. (2020). Linguagens e materiais expressivos em arteterapia. Wak.

Ross, H. (2021). 'I'm Dyslexic but What Does That Even Mean?': Young People's Experiences of Dyslexia Support Interventions in Mainstream Classrooms. Scandinavian Journal of Disability Research, 23(1).

Sampaio, C. T., \& Sampaio, S. M. R. (2009). Educação inclusiva: o professor mediando para a vida. EDUFBA

Santos, J. M. O. (2018). Considerações sobre o filme “Como estrelas na terra, toda criança é especial”. Ensaios pedagógicos, 2(1), $132-133$.

Sá-Silva, J. R., Almeida, C. D. D., \& Guindani, J. F. (2009). Pesquisa documental: pistas teóricas e metodológicas. Revista brasileira de história \& ciências sociais, 1(1), 1-15.

Souza, S. S. S. (2010). Uma forma criativa de ensinar: A arteterapia como ajuda à psicopedagogia através das artes plásticas. $<$ https://www.webartigos.com/artigos/uma-forma-criativa-de-ensinar-a-arteterapia-como-ajuda-a-psicopedagogia-atraves-das-artes-plasticas/54517>

Schweizer, C., Knorth, E. J., van Yperen, T. A., \& Spreen, M. (2020). Evaluation of "Images of Self," an art therapy program for children diagnosed with autism spectrum disorders (ASD). Children and Youth Services Review, 116, 105207.

S'lungile, K., Ugwuanyi, C. S., Okeke, C. I., \& Gama, N. N. (2020). Teachers' Experiences with Dyslexic Learners in Mainstream Classrooms: Implications for Teacher Education. International Journal of Higher Education, 9(6).

Spyropoulou, K. (2020). Children with dyslexia: Can they be included in mainstream contexts? European Journal of Special Education Research, 6(4).

Shella, T. A. (2018). Art therapy improves mood, and reduces pain and anxiety when offered at bedside during acute hospital treatment. The Arts in Psychotherapy, 57, 59-64. 
Research, Society and Development, v. 11, n. 1, e48611125127, 2022

(CC BY 4.0) | ISSN 2525-3409 | DOI: http://dx.doi.org/10.33448/rsd-v11i1.25127

Teoli, L. A. (2020). Art therapists' perceptions of what happens when they create art alongside their clients in the practice of group therapy. The Arts in Psychotherapy, 68, 101645 .

Urrutigaray, M. C. (2003). Arteterapia: a transformação pessoal pelas imagens. WAK.

Vender, M. \& Melloni, C. (2021). Phonological Awareness across Child Populations: How Bilingualism and Dyslexia Interact. Languages, 6(1), 39.

Winnicott, D. W. (2002). Os bebês e suas mães. Martins Fontes.

Wong, P. T. (2002). Logotherapy. 